\title{
VIEJA Y NUEVA MIGRACIÓN. Rasgos, supuestos y evidencias*
}

MARÍA JESÚS CRIADO

Universidad Complutense de Madrid

\author{
PALABRAS CLAVE ADICIONALES \\ ADDITIONAL KEYWORDS \\ Flujos migratorios, Mundialización, Determi- \\ nantes, Redes sociales, Cambio cultural. \\ Transnational Migration, Globalisation, Sources
and Factors, Social Nets, Cultural Change.
}

RESUMEN. El artículo revisa las diferencias más notables entre los flujos actuales y los precedentes. Se examinan después los diversos factores que intervienen en su génesis destacando, en este sentido, el papel de una serie de elementos de índole social y cultural. El proceso de mundialización, marco global en el que operan, sirve de soporte y potencia el efecto de estas dinámicas.

Desde el inicio de las grandes navegaciones de altura, en el siglo XVI, hasta bien entrado el siglo XX —-período de expansión europea-, los principales movimientos de población se han orientado, desde Europa, hacia el resto del mundo. Primero hacia el continente americano, más tarde hacia Asia, Oceanía y Africa. Lo característico en esos cuatro siglos fue, por tanto, la emigración europea sobre el conjunto del orbe, unido al arrastre de otras poblaciones que ello generó (en particular el desplazamiento forzoso de población africana para utili-

Este texto se encuadra en un trabajo más amplio, mi tesis doctoral - La línea quebrada. Historias de vida de migrantes (UCM, 1999) - en la que se examina la migración a y en España a partir de la perspectiva biográfica. Muchas de las ideas que aquí se apuntan se derivan de ese trabajo.

Revista Internacional de Sociología (RIS)

Tercera Época, n² 26, Mayo-Agosto, 2000, pp. 159-183. 
zarla como mano de obra esclava en América). La movilidad de la "frontera" de occidente es sólo un indicador visible de esa gigantesca expansión europea, un hecho de alcance histórico universal. Hasta el punto de que la situación actual, en términos de movilidad de la población, podría ser considerada como una inversión o reflujo de esa tendencia multisecular.

En efecto, la I Guerra Mundial y, sobre todo, la Segunda y la posterior descolonización, van a invertir por completo la tendencia. Se estima que la inmigración de postguerra a Europa superó los 30 millones de personas, haciendo de ella «uno de los más grandes movimientos migratorios de la historia humana» (Castles et al., 1984:1). Por lo que hace a los Estados Unidos, los datos relativos a los años 80 registran más de siete millones de inmigrantes, una cifra récord sólo comparable a los casi nueve que recibió en la primera década del siglo (naturales sobre todo de Europa). Ello es especialmente visible en las grandes ciudades, no sólo por el número o volumen de población extranjera, sino sobre todo por su variado origen, temas que con frecuencia se confunden. Así, se estima que en Los Angeles hay un $64 \%$ de población que pertenece a alguna minoría étnica y su tasa llega en Nueva York al 56\% la mayoría negros, hispanos o asiáticos, y, en buena parte, nacionales americanos. Pero en otras ciudades -y el modelo es Londres, con un $20 \%$ de minoría étnica-, la mayoría es emigrante y su composición variopinta. Un informe reciente revela que los niños londinenses comparten más de 300 lenguas diferentes, la mayoría africanas o de la india, y sólo dos tercios de los 850.000 escolares de esta ciudad, hablan inglés en su casa ${ }^{2}$. El multiculturalismo es, pues, una realidad cotidiana.

Lo característico de estas migraciones es la diversidad de las poblaciones de procedencia. En el caso de los Estados Unidos el 87\%, son asiáticos o latinoamericanos. Estos últimos superan, según la Oficina del Censo de EE.UU (1998), los 30 millones; más de dos viven Nueva York. Los menores de 18 años (10,5 millones) rebasan ya al colectivo de afroamericanos de la misma edad, principal minoría hasta ahora. En el año 2005 los latinos constituirán la primera minoría, y en el 2050 su número excederá al resto de las otras minorías juntas². A diferencia

'El estudio, denominado Capital Multilinguiística, ha sido elaborado por Philip Baker (Universidad de Westmister) y John Eversley (Instituto «Queen Mary and Westfield) y afirma a Londres como la capital con más diversidad linguística del mundo, por encima incluso de Nueva York. La concentración dialectal segmenta esta metrópoli en varias zonas. Así, en el centro y este de la ciudad, algo más de la mitad de los escolares (el $56,4 \%$ y $54 \%$ en cada una) hablan el bengalí; en el sur, un $30 \%$ se expresa en un idioma afrocaribeño, y en el norte, el $24 \%$ son hablantes del gujarati.

2 Ello está teniendo ya un importante impacto a escala social y política. La extensión del bilingüismo o la incorporación del español en las últimas campañas políticas son, entre otros, fieles reflejos del creciente peso de esta comunidad. 
de Europa, esa diversidad encubre, a su vez, otra más importante: el nivel sociocultural. El Censo americano de 1990 muestra grandes diferencias en variables tales como nivel educativo, ocupación, renta y grado de conocimiento del ingles. $\mathrm{Y}$ así, si el $60 \%$ de los inmigrantes a USA de India y Taiwan tienen estudios superiores, el porcentaje desciende al 5\% para quienes proceden de Camboya, Laos o México. De modo que, a la diversidad de origen, se añade la diversidad socioeconómica, dificultando así la elaboración de una política de integración válida para todos.

En España, el proceso ha sido similar aunque con cierta singularidad en cuanto a su ritmo. Agotada la emigración española a América después de la guerra civil, los años 60 presencian una amplia emigración del este, centro y sur de España hacia los principales centros industriales europeos. La imagen del trabajador/a español con una roída maleta en el tren camino del norte, pasó a formar parte del imaginario colectivo, como atestigua su presencia en la literatura, el cine y la música popular'. El proceso, sin embargo, se frenó en los años 70 y, en parejo, se inicia un lento retorno de emigrantes. Finalmente, a partir de los años ochenta, España se incorporará claramente a la pauta europea, transformándose de país de emigración en país de inmigración ${ }^{4}$. Con ello empieza a hacerse manifiesto también aquí la gran heterogeneidad que acarrean estos flujos. Si antes aludíamos a la situación en Londres, datos de la Consejería de Educación madrileña muestran que entre los 25.000 niños extranjeros escolarizados en Madrid en el presente curso (1999-2000), se cuentan 90 países de origen y 30 lenguas diferentes.

Vemos pues que el primer rasgo diferencial que distingue los flujos migratorios actuales de los anteriores, es que mientras aquellos ubicaban poblaciones occidentales (sobre todo europeas) sobre colonias y poblaciones igualmente europeas, éstos mueven poblaciones no-occidentales sobre los estados europeos. De modo que el flujo, en lo que respecta al espacio europeo, aparte de cambiar de tendencia, se orienta desde la periferia al centro (no al revés), y en lugar de mezclar poblaciones de origen básicamente europeo, mezcla población europea con otra no-occidental. Estos rasgos - centralidad geográfica (que no, obviamente, social) de la nueva emigración, predominio del origen no-occidental, y notable diversidad socioeconómica-, son señas capitales de estos procesos.

\footnotetext{
${ }^{3}$ Se calcula que entre 1959 y 1974, más de dos millones y medio de personas, entre trabajadores y familiares, emigraron a otros países europeos, lo que representaba cerca de un $6 \%$ de la población general y un $10 \%$ de la población activa.

+ Esta transición, según A. Izquierdo (1992), se cubrió en una década y su núcleo se sitúa entre 1985 y 1991. Ello no obsta para que todavía la cifra de españoles en el exterior - que supera los 2 millones - sobrepase con creces la de inmigrantes recibidos: unos 720.000 (Anuario de migraciones 1996 y Anuario estadístico de extranjería Año 1998).
} 
A ellos se añade otra serie de aspectos, que afectan a las pautas y perfiles «clásicos» que van a cuestionar muchas de las tesis y supuestos de las teorías convencionales. Así, en otras fases mignatorias, los flujos de inmigración estaban compuestos de forma mayoritaria por los miembros adultos de las clases trabajadoras, generalmente varones, que se movilizaban a partir de una demanda, con un objetivo concreto y, al menos en lo que toca a Europa, con la perspectiva del regreso. Era por tanto una migración inducida, delimitada y temporal. Nunca se pensó que su presencia tuviera efectos importantes en la sociedad receptora, más allá de los meramente económicos. Respecto al modo de integrarse en ésta, respondía al modelo de «asimilación» cultural en el que, además, incumbía al inmigrante la tarea y el esfuerzo necesario. Pero ahora el arquetipo señero muestra fracturas en todos los frentes. Nuevos modelos de inmigrantes se suman al anterior y añaden variedad - y por ende, complejidad - a este viejo fenómeno (A. Izquierdo, 1996). Los móviles se multiplican y, con ellos, los tipos de emigrantes $^{5}$. La emigración familiar se afirma como dinámica y, de hecho, constituye la categoría más numerosa en las entradas de migración regular (SOPEMI, 1998). Aumentan las mujeres que emigran solas, con un proyecto autónomo, al igual que el número de adolescentes, y crece también el de personas mayores y de niños. Por otro lado, la emigración temporal deja paso sin vacilación a asentamientos permanentes. Asimismo, frente al modelo de homogeneidad anterior, se reclama el derecho a la diferencia en el marco de una convivencia multicultural' ${ }^{6}$.

Son tantos los rasgos diferenciales que sellan el contraste con los movimientos migratorios anteriores que bien puede hablarse, y así hará J. Arango (1992), de una «nueva era» en la trayectoria de este viejo fenómeno. Sólo para recapitular y dar breve cuenta, anotamos algunos de los más destacados en la siguiente relación:

a) Su globalidad y complejidad intrínseca, en varios sentidos. Primero, porque afectan a un mayor número de países y regiones y se conectan con una miscelánea de proceso de ámbito planetario. Después, aunque no en segundo lugar, por los motivos y efectos agregados, que sobrepasan con mucho la esfera económica y se extienden a las esferas política, social y cultural, y por lo plural de su composición, que dificulta las tareas de "abordaje" en los diversos frentes (social, político y teórico) (Castles y Miller, 1993; Izquierdo, 1998).

\footnotetext{
${ }^{5}$ A los migrantes tradicionales (movidos por razones económicas o políticas) se unen ahora otros grupos sociales: profesionales y técnicos, estudiantes, jubilados y pensionistas, deportistas, etc. La movilidad de la población adopta tal elenco de formas que hacen imposible subsumirlas en una clasificación unívoca.

'Charles Taylor (1992); Z. Bauman (1994); E. Lamo de Espinosa (1995); A. Touraine (1995).
} 
b) Respecto a su orientación, predomina a nivel general el sentido Sur-Sur; éstos serán los más cuantiosos pues, aunque los flujos migratorios se producen hoy en todas direcciones, la mayoría tienen carácter regional y los migrantes suelen dirigirse a los países limítrofes (Arango, 1992; Izquierdo, 1996). No obstante, en relación al espacio europeo, lo más llamativo es la inversión que suponen respecto a la trayectoria anterior al afirmarse gradualmente el desplazamiento del Sur al Norte (Arango, 1992).

c) No sólo aumentan los «lugares migratorios», también, y como advierte A. Izquierdo, se hace cada vez más patente el cruce entre las dos caras que presenta este fenómeno, al coexistir ambas facetas en numerosos estados; es decir, por primera vez aparecen países que ejercen a la vez como emisores y receptores de migrantes (Izquierdo, 1996). Con ello se apunta como otro aspecto más el sesgo híbrido, que definirá este comportamiento en gran parte de estados. Marruecos, Polonia, México, la Rep. Dominicana, Indonesia, y un largo etcétera, sin excluir tampoco a los países avanzados, envían emigrantes a la par que los reciben.

d) La diversificación en todos los órdenes -origen (nacional, social y cultural), motivos, proyectos de vida, confesiones, etc.- , genera una gran variedad de perfiles y de modelos de asentamiento. Las migraciones actuales ya no atienden a modelos simples basados en pautas genéricas, tal como subrayan Portes y Börözc para quienes, «en términos generales, la única generalización justificable es la diversidad de modos de acceso de la inmigración contemporánea a los países avanzados y los resultados económicos y sociales muy distintos a que dichos modos de acceso dan lugan» (Portes y Börözc, 1992:31). Ello implicará a su vez, mayor dificultad para proyectar medidas generales de integración (Izquierdo, 1998).

Carácter espontáneo, estabilidad de las corrientes migratorias e independencia de las condiciones que les dio origen. Es patente que los desplazamientos actuales no son fruto de una demanda expresa de los países de destino, y, de igual modo, la experiencia, europea y americana, muestra cómo una vez que los flujos se ponen en marcha se emancipan gradualmente de los móviles iniciales y generan su propia lógica que será el nuevo motor que los alimente (Massey, 1987; Portes y Börözc, 1992; Arango, 1992). Ello va a tener consecuencias imprevistas al llegar a su fin a la par los dos modelos que guiaron las migraciones anteriores - poblacional y laboral- lo que lleva a políticas restrictivas de la migración y repercute también en la posición y condiciones de vida de los migrantes, definidas en gran parte ahora por una mayor precariedad laboral y legal (Solé, 1995; Martín Serrano, 1993, Izquierdo, 1998).

Creciente incorporación de la mujer como migrante autónomo - sola o al frente de familias monoparentales-, consolidación del carácter familiar, tendencia al asentamiento, que se afirma frente al retorno, y aumento constante de la migración irregular (Izquierdo, 1996).

- Rechazo de la asimilación como vía de integración y demanda de la propia identidad. 
- Importancia tácita de los factores culturales. Su presencia efectiva en la génesis de la migración - que incorpora como un determinante más la extensión de patrones culturales ajenos al propio contexto-, y en la problemática que se plantea en las sociedades de destino - escenarios de manifiesta heterogeneidad-, realzan este elemento y le otorgan un lugar destacado en el análisis.

- Su visibilidad. Por primera vez en la historia somos testigos de la movilización masiva de población. Los media nos ponen frente a la evidencia de este proceso y nos convierten en espectadores del mismo. La conciencia de que la realidad y el entorno se trastocan, aumenta con ello, a la vez que se agudiza la inquietud que acompaña a toda modificación rápida de los referentes cotidianos.

Como suele ocurrir, los cambios en la realidad, dejan obsoletas las principales teorías que intentan entenderla y definirla. $\mathrm{Y}$ así ha ocurrido con los paradigmas que explicaban las migraciones y la integración de los inmigrantes a partir de modelos simples fundados en diversas asimetrías. Sus defectos se reflejan en su incapacidad para explicar las pautas observadas en los flujos migratorios: la respuesta dispar de los países, en volumen y sentido —cuestión que afecta a las condiciones macroestructurales-, y las tendencias que presentan los individuos de un mismo país y región - lo que incumbe a las causas microestructurales de las emigración (Portes y Böroz, 1992). La estabilidad de los flujos una vez que desaparecen o disminuyen las ventajas comparativas, bien por un mayor desarrollo del país de origen o porque mengua la probabilidad de hallar trabajo; la orientación - los emigrantes no siempre se dirigen a las áreas de mayor desarrollo económico- y la selección de los sectores implicados — por qué no afecta por igual a todas las zonas del país o, en un nivel superior, a países con situaciones similares-, son algunas de las cuestiones que ponen de relieve las limitaciones y restan validez a las líneas explicativas clásicas de la migración. Los investigadores de este campo, en consecuencia, van a modificar las anteriores perspectivas e incorporan nuevos criterios en su examen y análisis (Wood, 1992).

\section{VIEJAS RAZONES Y NUEVOS AGENTES}

La investigación científico social de las migraciones, heredera en una gran parte de los presupuestos establecidos por Ravenstein (1834-1913), ha enfatizado tradicionalmente las motivaciones económicas como fuente principal. Para este autor, que llega a formular una serie de «leyes» explicativas de las migraciones ${ }^{7}$,

\footnotetext{
${ }^{7}$ Los trabajos de Ravenstein (1885 y 1889), en los que analiza las migraciones laborales de zonas rurales a urbanas, se consideran los primeros estudios sistemáticos de los movimientos migratorios. J. Arango examina la aportación de este autor en su articulo: «Las 'Leyes de las Migraciones' de E. G. Ravenstein, cien años después», REIS n ${ }^{\circ} 32$, 1985, pp 7-26.
} 
son las desigualdades económicas las que impulsan a un sector de población generalmente hombres en edad laboral que proceden de zonas rurales densamente pobladas en las que las posibilidades de progresar son muy bajas-, a desplazarse a otros entornos que requieren mano de obra y ofrecen mayores expectativas de logro económico. Fiel a esta línea; el pensamiento ortodoxo - tanto desde premisas funcionalistas como desde la perspectiva marxista- ha venido privilegiando los factores demográficos y económicos para explicar, desde una lógica mecanicista, los desplazamientos entre países. Y así, la aceptación global de una serie de preceptos aparentemente lógicos - basados bien en una hipotética racionalidad o bien en la inevitable condición de explotación que domina las relaciones de producción - ha supuesto una limitación a la hora de entender las movilizaciones actuales. La heterogeneidad manifiesta de los componentes, así como la orientación y comportamiento de los flujos, escapa en gran parte a los postulados defendidos desde esas perspectivas teóricas. De ahí que los argumentos clásicos —desigualdad estructural, optimización de oportunidades, presión demográfica - pierdan fuerza como razones absolutas al tiempo que se incorporan nuevos elementos que resultan más eficaces en la fase actual.

La enorme variedad y complejidad que presentan los flujos hoy, dificulta la labor de hallar una perspectiva teórica omnicomprensiva, capaz de dar cuenta y explicar en su conjunto este fenómeno. En este sentido se expresan diversos estudiosos del tema que empiezan a descartar la posibilidad de llegar a una teoría general proponiendo en su lugar diversos marcos teóricos, que utilizados a la manera de teorías de rango intermedio, sirvan para aclarar los determinantes de la migración .

Por lo común se atribuye este hecho a una serie de factores que presionan sobre las dimensiones de los flujos haciendo de este fenómeno una tendencia mucho más masiva. De éstos, los más reiterados son: la desigualdad entre Norte y Sur, los conflictos internos, la difusión de valores y de estilos de vida del mundo occidental, las redes migratorias, la interconexión planetaria y facilidad de comunicaciones, la segmentación del mercado de trabajo, la presión demográfica en los países del tercer mundo y el deterioro medioambiental". Pero nin-

\footnotetext{
${ }^{8}$ Es ésta una idea general que se reitera en los últimos años en los congresos sobre el tema, y en ello se insistió en la Conferencia sobre «International Migration Challenges for European Populations», organizada por l'European Association for Population Studies i la Universitat de Bari, a Bari (Italia), 25-27 de junio, 1998. En este sentido, A. Izquierdo (1996; 1998), hará hincapié en el "reto teórico" que suponen las nuevas migraciones y la dificultad de enunciar un modelo explicativo único.

"Es ésta una idea general que se reitera en los últimos años en los congresos sobre el tema y en ello se insistió en la Conferencia sobre "International Migration Challenges for European Population", organizada por l'European Association for Polpulation Studies i la Universitat de Bari, a Bari (Italia), 25-27 de junio, 1998. En este sentido, Izquierdo (1996; 1998), hará hincapié en el "reto teórico" que suponen las nuevas migraciones y la dificultad de enunciar un modelo explicativo único.
} 
guno de los factores que median en las movilizaciones actúa de modo aislado. Lo que caracteriza los flujos migratorios actuales en este sentido, es la interrelación y dependencia que mantienen entre sí todos ellos, de ahí que las posibles recetas que se consideran para frenarlas tengan pocas posibilidades de éxito.

En efecto, empieza a haber acuerdo respecto a los muchos determinantes que median en la decisión de emigrar. Detrás de ella, más que una sola causa, opera un abanico de razones que incumben a tres niveles diferentes: el marco de decisiones individuales, la trama familiar y social y el contexto económico, social y político que define la vida en el país. No hay que olvidar, por otra parte, que las migraciones, como todo fenómeno histórico, guardan relación con el contexto en que se producen, que en este caso remite directamente, por primera vez en la historia, a estructuras y procesos de orden planetario. Los efectos añadidos de este hecho en el ámbito económico y cultural lo señalan como extremo a considerar en primer lugar. Al impacto de la globalización se suma la acción de las redes migratorias y las derivaciones de los vínculos entre países. Estos elementos se constituyen en los ejes básicos de referencia a la hora de entenderlas (Sassen, 1988; Portes y Rumbaut, 1990, Massey, Alarcón, et al, 1987). Juntos afirman el desplazamiento transnacional como un proceso estructural, de naturaleza social, que hunde sus raíces en la trayectoria -histórica y reciente-de los respectivos países.

Existen diferencias de criterio respecto al alcance que tiene cada uno de los factores estipulados más comúnmente. Así, Saskia Sassen (1988) y Portes y Rumbaut (1990), entre otros, sostienen que las variables convencionales -pobreza, retraso económico y superpoblación - no explican por sí mismas el hecho migratorio y defienden la necesidad de considerar la acción de otras variables. Si así fuese - argumentan-, sería de esperar que los mayores flujos correspondiesen a los países con mayores déficits económicos y estructurales, algo que la realidad no siempre respalda: países con cierto grado de desarrollo presentan tasas suficientes de desplazamientos al exterior, mientras en otros más pobres no es habitual tal práctica. Es obvio que todos estos factores van a tener alguna incidencia pero, como estos autores insisten, ninguno será determinante ni de que se produzcan flujos migratorios, ni de sus dimensiones, ni tampoco de la orientación que siguen. La explicación al origen, argumentan, se halla en las relaciones previas - políticas y económicas-que vinculan entre sí a países emisores y receptores de emigración que tiene lugar en unas condiciones marcadas por la asimetría de poder entre ellos (Portes, 1979; Sassen, 1988; 1994).

Los flujos migratorios son, según Sassen (1988), una consecuencia añadida de los procesos que se derivan de dichas conexiones. Su tesis central liga, en concreto, las migraciones laborales externas a la internacionalización de la producción; el nexo entre ambas serán las inversiones extranjeras en los países menos desarrollados. El complejo alcance que, en última instancia, supone esta afirmación ${ }^{10}$, hace que Sassen se muestre cauta en su análisis y recalque que no 
son propiamente las inversiones extranjeras lo que genera la emigración, sino que surge como resultado de la estructura que se origina a partir de aquéllas; será ésta la que propicie la opción de la emigración. Mediando entre ambos procesos -inversión extranjera y migración - estaría la trama de relaciones que se dan entre los países a partir de dichas inversiones y en la que la circulación de individuos sería un aspecto fundamental. La creación de puestos de trabajo no supone, como podría preverse, un freno para la migración debido a los efectos que esas transacciones tienen en la estructura ocupacional y productiva del país emisor y a los vínculos que se crean a nivel cultural e ideológico entre ellos a raíz de las mismas. La destrucción de las estructuras tradicionales, con la consiguiente salarización de mayor parte de población, y el empleo preferente de mujeres en las nuevas empresas que se crean para la exportación, cuyos bajos salarios impulsan a emigrar - efectos directos de las inversiones-, sirven de argumento y apoyan la relación que establece Saskia Sassen".

En sentido análogo, A. Portes y J. Börözc (1992), atribuyen la dinámica migratoria a la intervención de los países más poderosos que impulsará, de modo directo o secundario, desplazamientos. Esa «injerencia externa» que recalcan, se efectúa ahora mediante la difusión cultural de los patrones de consumo ${ }^{12}$. Las

\footnotetext{
${ }^{10}$ En síntesis, la nueva explicación, al afirmar el efecto movilizador de las inversiones externas, va a poner sobre el tapete el papel que juega en las migraciones la implicación activa en el desarrollo de los países emisores, elemento que siempre se ha considerado antídoto de los flujos. Ésta es, en el fondo, una de las conclusiones del estudio de S. Sassen sobre las migraciones del Sudeste Asiático a EE.UU, flujo que coincide con una fase de elevado crecimiento económico en los países de origen (que supone en algunos entre el 5 y $9 \%$ del PIB) y ascenso a la par de la inversión de los EEUU.

"En el contexto de nuestro país, uno de los estudios que confirman estas observaciones es el coordinado por R. Aparicio y A. Tornos (1997) sobre la migración peruana a España. De las tres oleadas que señalan en este flujo $(1987,91$ y 94$)$, las dos primeras coinciden con fuertes crisis económicas en Perú, mientras que la tercera corresponde a una fase de clara recuperación y crecimiento económico. Una posible explicación que apuntan, sería que el ascenso económico permite emigrar a aquellos que, en plena crisis, carecían de medios para afrontar un proyecto migratorio, efecto que coincidió, además, con una maduración de las redes migratorias que se habían ido conformando en los años anteriores. Por otro lado, también observan el impacto que suponen, en la imagen de nuestro país, la celebración del Quinto Centenario del «descubrimiento» y las inversiones españolas de la última década (sobre todo las de Telefónica, el Santander y el BBV). Ambos sucesos, que calan fuertemente en la opinión pública, coinciden con un incremento de la migración peruana a España. El estudio muestra que en ese tiempo pasa a ocupar un lugar preferente en el conjunto de países elegidos para una potencial emigración, casi al mismo nivel que EE UU e Italia, destinos favoritos tradicionales.

${ }^{12}$ A. Portes y J. Börözc (1992) distinguen tres fases sucesivas en la historia migratoria en las que rige un modelo diferente de movilización de mano de obra, vinculado a su vez con el «modo de penetración» de las instituciones de la nación más poderosa en las subordinadas. Así, la «coerción
} 
migraciones actuales responderían así a la incorporación de nuevas «necesidades» en las sociedades periféricas que reflejan el modelo difundido desde los países avanzados. La dificultad de cumplir las expectativas que generan en una economía de escasez y los crecientes vínculos transnacionales permiten a algunos grupos buscar una solución mediante la emigración. Como telón de fondo se halla una larga historia de relación previa que ha tejido una tupida malla que vincula poblaciones y países.

Los flujos contemporáneos, tanto los que vienen a Europa -originarios de las antiguas colonias y el sistema Gastarbeiter--, como las que llegan a EE.UU desde el sudeste asiático (Corea del Sur, Taiwan y Filipinas), la República Dominicana, o Puerto Rico, apoyan la tesis que las condiciona a la existencia de vínculos previos -objetivos e ideológicos, en términos de Sassen-entre los países implicados (Portes, 1979; Sassen, 1988). Las relaciones políticas y económicas entre los países emisores y los receptores constituyen, según Portes y Rumbaut (1990:24), la macroestructura de los procesos migratorios. Éstas conformarán las condiciones iniciales que los hace posibles. Los movimientos migratorios, en sus propios términos, «tienen sus raíces en la historia de las relaciones políticas y económicas entre los países emisores y receptores. A través de esos procesos se moldean contextos que hacen inteligibles los cálculos acerca de los costos y beneficios de la emigración» (Portes y Rumbaut, 1990:230).

Esta tesis, que condiciona la movilización de la población a la existencia de unos vínculos previos entre los países, pone de manifiesto la incoherencia de las reacciones de sorpresa que provocan en los países receptores. Pues, en realidad, a lo que asiste el mundo de hoy es a la reverberación de la actuación de esos países en el pasado - más o menos lejano-que han generado lazos muy poderosos entre realidades distantes. Las migraciones actuales son, en una gran parte, el reflujo de esa intervención anterior, una de las maneras en las que se expresan, a la vez que se prolongan y mantienen, los vínculos preexistentes.

Desde otra posición, Myron Weiner (1987) cuestiona también la capacidad explicativa de las condiciones demográficas y económicas de los países emisores como origen de los flujos. Weiner afirma que en general no hay evidencia de que las tasas de emigración y las de crecimiento de la población estén relacionadas. Las pautas observadas en una serie de países a este respecto, muestran que no siempre coinciden ambos procesos y que incluso puede darse la situación contraria. Es decir, existen países con bajo índice de crecimiento (p. e. Grecia y Portugal) o con cifras similares a las de los países desarrollados (Turquía entre

física», propia de la colonización, deja paso al «reclutamiento deliberado» mediante el «aliciente económico», que domina gran parte del siglo XX, mientras que en la fase actual, el movimiento es inducido de modo indirecto (exportación del modelo de constumo). 
ellos) que presentan altas tasas de emigración; o bien flujos que van de países con crecimiento alto, a otros que incluso lo tienen más elevado (la emigración de Colombia, p. e., que en los años 60 creció un 3\% y en los 70 un 2,3\%, se dirigía mayormente hacia Venezuela que presentaba una tasa de crecimiento del 3,3\%). Esta afirmación general no implica, por otro lado, que en ciertos contextos esta variable resulte significativa. No obstante, y como apunta Arango (1992), su importancia radica más en su relación con el potencial migratorio que con los flujos efectivos.

De igual modo, en su estudio sobre la emigración internacional y el tercer mundo, Weiner constata que en determinados casos, «las tasas medias de crecimiento económico per cápita de muchos países con emigración alta no son menores y en muchos casos superan las de los países a los que estas poblaciones emigran" (Weiner, 1987:176). Así ocurre en los casos de México, que entre 1963 y 1980 tenía una tasa de crecimiento económico más alta que la de los Estados Unidos; en el de Turquía, Grecia y Yugoslavia, que crecían más que Alemania; o en el de Colombia, cuyo crecimiento se sitúa por encima del de Venezuela. De estos datos deduce que «la emigración económica a los Estados Unidos, a Europa Occidental y los países productores de petróleo está primariamente inducida por la demanda, no por la oferta» (Weiner, 1987:176).

Si los procesos que vinculan a los países receptores con los de origen están en la raíz de los flujos (Sassen 1988; Portes y Rumbaut, 1990), parece tangible que la demanda de trabajadores en los países receptores contribuye, en mayor o menor medida, a mantenerlos. Más cuando la economía sumergida y la existencia de nichos laborales sin cubrir en los países desarrollados requiere continuamente mano de obra poco cualificada y dispuesta a aceptar condiciones irregulares de trabajo. En este sentido abunda M. Piore (1979), quien sostiene que por encima de las condiciones deficitarias de los países emisores, influyen los factores de atracción en los receptores debido a la necesidad estructural de reclutar trabajadores extranjeros. Según este enfoque - conocido como teoría del mercado de trabajo dual y basado en su segmentación-, con independencia de las motivaciones que orientan las decisiones individuales, las migraciones internacionales se producen por la demanda intrínseca de las sociedades industriales modernas. El peso de la economía sumergida será fundamental a la hora de explicar el incremento de la inmigración irregular a Europa y sobre todo en lo que respecta a los países meridionales.

En un mercado laboral en el que abundan los empleos precarios, con condiciones de trabajo abusivas, e incluso peligrosas, y mal remunerados, habrá una serie de demandas concretas que la población nativa, incluso en situación de paro elevado, no va a satisfacer. Sobre todo si existe una experiencia reciente de un ascenso social importante. Además determinados sectores - agricultura, construcción, hostelería, entre ellos- tienen importantes fluctuaciones en la demanda de mano de obra. El trabajo intensivo, temporal y en condiciones adversas, 
dominan en estos sectores. Los inmigrantes extranjeros resultan más flexibles y dóciles que los trabajadores nativos y se adaptan mejor a este tipo de demanda.

Este diferencial de ventajas, que inclina la balanza a favor del foráneo, ya lo detectó Weber en su «Ausblick» ${ }^{13}$. La primera de sus conclusiones va justamente en ese sentido al indicar cómo la utilización de trabajadores extranjeros permite el aprovechamiento exhaustivo de una fuerza de trabajo limitado al tiempo en que se necesita, es más dócil y, además, evita adquirir compromisos. Por todo ello resulta bastante más barata:

«La razón de que se recurra a trabajadores itinerantes, también allí donde se puede disponer de trabajadores nativos, se basa en parte - pero sólo en parte- en los sueldos absolutamente bajos que les son pagados a aquéllos; pero en general —aparte de en la mayor docilidad de los extranjeros, en posición precaria- en que es posible un aprovechamiento exhaustivo de la mano de obra en verano sin la necesidad de encargarse de ella también en el invierno, y sobre todo, sin tener que aceptar obligaciones jurídico-administrativas, $u$ otras, que existen frente a trabajadores nativos. En este sentido es aquélla siempre más barata para el empleador» (Weber, 1990:243).

Pero además, y aunque suele insistirse en lo contrario, sigue existiendo una demanda expresa; la diferencia respecto a otras fases migratorias es su carácter sumamente selectivo. Algo, por otra parte, no tan novedoso. Lo que ahora la distingue es, sobre todo, el atributo que se prima. Antes era mera energía mecánica (como "fuerza de trabajo", elemental); hoy, «conocimiento», el saber en su vertiente de destreza específica, un instrumento básico para el avance de la técnica. De ese factor, que determina hoy, en gran parte, el crecimiento potencial, depende el poder (desigual) de los estados y, por ende, la posición que ocupan en la estructura jerárquica. Y a ello responde la aprobación reciente en EE.UU de una ley que incrementa ampliamente (casi el 100\%) la cifra de visados anuales de residencia que se conceden a extranjeros cualificados (pasa de 65.000 a 115.000), y que contó con fuertes presiones empresariales (de sectores de tecnología punta: telecomunicaciones e informática, sobre todo). Un camino que ha seguido después Alemania, que levanta excepcional y temporalmente la veda migratoria para cubrir su «parque» de informáticos y al que parece que se

\footnotetext{
${ }^{13}$ Max Weber: «La situación de los trabajadores agrícolas en la Alemania del Este del Elba... (1892), Revista Española de Investigación Sociológica, núm. 49, Cis, Madrid, 1990, pp. 233-255. $\mathrm{El}$ informe de Weber se inscribe dentro del bloque de estudios e informes que impulsó la «cuestión agraria» a finales del XIX en Europa. La crisis agraria provocó desplazamientos de los cultivos y un incremento de las tensiones sociales. Las características propias del sector agrario, que requiere de un número desigual de trabajadores a lo largo del año, es el primer factor que va a señalar.
} 
irán incorporando otros países avanzados a la caza de «cerebros», entre ellos el nuestro según predicen y aconsejan estudios recientes.

Junto a los procesos antedichos, las redes migratorias se afirman como factor definitivo en las migraciones internacionales recientes (Massey y García España, 1987; Boyd, 1989, Portes y Rumbaut, 1990; Glick-Schiller et al, 1992; A. Izquierdo, 1996; Fawcett, 1989). De ahí que se consideren como un nivel de análisis diferenciado y complementario de las estructuras socioeconómicas y políticas. Si las últimas conforman las «macroestructuras» de la migración, las redes - elemento clave de las «microestructuras»-constituyen la urdimbre que la facilita manteniéndola como un proceso social autosuficiente (Portes y Rumbaut, 1990:224-232). Éstas desarrollan una función capital en el hecho migratorio al conectar individuos y comunidades que residen en lugares distintos y ofrecer la posibilidad de desarrollar estrategias lejos del lugar de origen. De este modo, las redes van a posibilitar una "desterritorialización"'14 paulatina que será la base para la formación de comunidades transnacionales (Glick-Schiller et al, 1992).

Las redes migratorias darán respuesta a dos importantes cuestiones sin resolver por las teorías convencionales: el carácter selectivo de la migración -manifiesto en las diferencias individuales (por qué, en similares condiciones, no todos emigran), y en la concentración espacial (en lugares de origen y en destino)-, y la estabilidad de los flujos (que se independizan de las condiciones y alicientes económicos iniciales). Constituyen, por tanto, el otro eje esencial en el estudio de las migraciones internacionales, pues son las que explican los comportamientos, aparentemente aleatorios y erráticos, de los individuos que se desplazan y, con ello, la configuración y estabilidad de las corrientes migratorias. Los movimientos migratorios dejan de ser entendidos como un fenómeno esencialmente económico y pasan a reconocerse como manifestación de procesos sociales más complejos ${ }^{15}$. En esta línea, Portes y Boröcz (1992:25) van a definir la migración laboral «como un proceso de progresiva construcción de redes».

Su intervención en la movilización de la población, generalmente a través de lo que se conoce como «cadenas migratorias», es determinante en dos cuestiones básicas: en la alimentación y consolidación de la corriente migratoria, al fomentar nuevas migraciones, y en la orientación que siguen los flujos entre un determinado origen y destino. La razón está en que posibilita al emigrante potencial

\footnotetext{
${ }^{14}$ Con este término quiero indicar la desaparición de un vínculo rígido entre una comunidad y un territorio.

${ }^{15} \mathrm{El}$ hecho de que la migración actual sobrepase la dimensión económica y se afirme en cuanto fenómeno social, cultural y político, resta protagonismo a las disciplinas que se venían ocupando de ella (economía y demografía) y lo traslada a otras áreas del saber. Entre ellas, la sociología, la antropología y la política (Izquierdo, 1998).
} 
una serie de recursos a través de las redes de relaciones previas - basadas en vínculos de parentesco, amistades o comunales- que pueden activarse en el proceso, y que serán decisivas en el desarrollo de la experiencia migratoria.

Es obvio que la emigración requiere de unos recursos previos que se han de movilizar para superar los obstáculos intermedios entre origen y destino. Dentro de esa gama de recursos, los más valorados son los que atañen a la información y el apoyo en la etapa inicial, aspectos que se cubrirán a través del conjunto de relaciones que conforman la red social del inmigrante. De ahí que ésta constituya una pieza clave de lo que Coleman (1988:84) ha denominado capital social ${ }^{16}$.

A través de las redes de relaciones fluyen tanto información como otros recursos. Sirven como sistema de seguridad financiera, ayudan a encontrar trabajo, proporcionan alojamiento y son fuente de información de todo tipo. Pero, junto a esta faceta instrumental, la red da respuesta también al conjunto de necesidades que conciernen a la dimensión expresiva. En este sentido, contribuyen a amortiguar el coste emocional y afectivo que supone la separación de los más allegados y del universo natural de referencia. A través de ellas se actualizan los vínculos y obligaciones con aquéllos y con la comunidad de origen. Todo ello las convierte en una importante subcorriente que se mueve a menudo en dirección contraria a las tendencias económicas globales. Gracias a ellas las variaciones salariales y las oportunidades de empleo se nivelan, de modo que en un cierto tiempo el volumen del flujo es relativamente indiferente a las fluctuaciones del ciclo económico en los lugares de destino (Portes y Börözc, 1992).

La evidencia muestra que una vez que se inician procesos migratorios, tienden a mantenerse aunque se modifiquen las circunstancias y condiciones dominantes en el momento de su inicio (Massey, 1987; Portes y Börözc, 1992 ). Asimismo, se constata que, con independencia de los factores concretos que actúan en cada caso, lo cierto es que las migraciones siguen rutas muy definidas (Ackerman, 1976; Arango, 1985; López, 1992). Esto es, origen y destino no se conectan al azar sino que existen fuertes relaciones entre ciertas áreas de uno y otro polo que fijan un determinado itinerario. Este hecho se explica, en primer lugar, por los vínculos previos entre países que preceden al nacimiento de los flujos (Portes, 1979; Sassen, 1988). Pero otro elemento decisivo, es el stockeffect, es decir, la influencia que los propios migrantes en un lugar concreto

\footnotetext{
16 Coleman (1988), que incorpora esta modalidad al acervo de recursos personales junto al capital material y al humano, indica que el capital social está integrado por una serie de efectivos que tienen en común dos características básicas: todos ellos forman parte de algún aspecto de la estructura social, y además facilitan la acción dentro de la misma. La red social del inmigrante, en cuanto está integrada en la estructura social y supone una fuente de recursos, sería un componente importante de ese cúmulo.
} 
ejercen sobre los que permanecen en los lugares de origen. Ésta se produce a través de la información, del ejemplo que supone haber superado los obstáculos, del "efecto-demostración" manifiesto en las remesas enviadas a sus familiares, y también por medio de la inducción directa mediante la oferta de empleo, de alojamiento, o el envío del costo del pasaje (Arango, 1985).

Las cadenas y redes migratorias son los agentes de los procesos señalados y por tanto uno de los factores que más ayudan a explicar las diferencias y regularidades observadas, a escala de individuos y áreas, así como la estabilidad de los flujos por encima de las condiciones externas. De ahí la atención que se les concede en los estudios actuales. Su incorporación al análisis de las migraciones ayuda a entender las divergencias evidentes al conectar las condiciones objetivas (nivel macro) que actúan en la migración y las conductas individuales (nivel micro). Y es que, tal como advierten Portes y Bach (1985), los vínculos sociales establecidos en el otro país pueden ser un estímulo a la hora de decidir emigrar, al ofrecer más seguridad que las ventajas materiales derivadas de las condiciones objetivas.

El testimonio de una inmigrante de origen peruano, que relata los aspectos considerados en la toma de decisión, permite apreciar la intervención de los elementos citados hasta ahora: vínculos previos (históricos y económicos), demanda laboral y redes sociales:

«...Entonces, se vio la posibilidad de España. Claro, la mira de Europa era España por el idioma, porque .... los demás países, ninguno tiene el español, sólo España, y siempre se ha considerao España como la madre patria y todo eso. Entonces, se empezó emigrando a -España (..) Nosotros nos relacionamos con esta emigración por un matrimonio, amigo de mi cuñada.(...) Ellos llegaron a España, porque dijeron que en España, trabajo para hombres, y la mujer de uno de ellos se fue a Italia, porque dijeron -en ese entonces en Italia estaba emigrando mucha gente-, que había trabajo para mujeres. (...) Mi cuñada era amiga de éstos que vinieron y entonces ya se tenía que venir la mujer de él y tenía dos niños, y no sabía a quién dejárselos. (...) y como era amiga con mi cuñada, le propuso, que, por favor, se quedara en su casa, que cuidara de sus hijos y que ella le ofrecía pagarle el viaje para España, que estaba mejor allá...»

Finalmente, una vez asumido que la desigualdad en sí misma no lo explica todo - si fuera así, cabría preguntarse, como anotan J. Arango (1992) y A. Izquierdo (1996), por qué hay tan pocos migrantes frente a tanta adversidad-, habrá que considerar entre las variables involucradas aquellas que atañen al orden cultural y las de índole psicológica, ingredientes importantes y hacia las que, de alguna manera, nos orienta Max Weber en el informe al que me referí antes.

En efecto, en su examen del éxodo que acompaña a la «crisis agraria», Weber, al tiempo que advierte de que «toda consideración puramente económica sería poco realista» (op. cit. p. 248), va a afirmar el papel de las aspiraciones subjeti- 
vas individuales en la decisión de emigrar. En concreto, sostiene que, si bien es cierto que la penetración de las relaciones capitalistas en el campo genera una dinámica ajena a la propia voluntad de los actores, la migración no es sólo una cuestión de meras relaciones objetivas. Los trabajadores dejaban la hacienda, emigraban, no sólo porque fueran expulsados, también había algo que les atraía fuera, y que dominaba sobre la seguridad que les proporcionaba aquélla. El deseo de los campesinos de escapar de su anterior relación con la tierra prevalecía, aunque el precio de esa libertad fuese una peor condición económica. Una conclusión a la que llega al constatar que «por mucho que se mejore la situación material de la servidumbre - los salarios de éstos se pueden calificar de buenos- disminuye crecientemente el número de los siervos alimentados en casa» (op. cit., p. 237). Con ello, Weber pone de relieve una aspiración novedosa -el deseo de independencia. Ésta se va a sumar a los factores económicos determinando la trayectoria de los trabajadores agrarios en el sentido de una mayor autonomía de la hacienda, a la par que se refuerza el individualismo. Sus palabras no dejan sombra de duda sobre la fuerza que posee tal factor:

«La tendencia más acentuada, especialmente entre los elementos más capaces del conjunto de trabajadores, es a la separación de la comunidad familiar y de la economía patriarcalista a toda costa, incluso al precio de convertirse en propietario sin hogan» (Weber, ob. cit., p. 246).

De ahí que Weber insista en su informe en la necesidad de contemplar la evolución en las necesidades psicológicas, ya que muchas veces su peso es mayor que el de las variaciones que afectan a las condiciones materiales de la vida. Su recomendación parece hoy igual de pertinente en el asunto que nos ocupa. Así, debemos considerar, como un elemento específico, los cambios en las aspiraciones subjetivas individuales que resultan de la difusión de una serie de ideas, valores y patrones de conducta, propios en origen del orbe occidental, que amplían su radio de acción más allá de ese universo transformándose en referentes cada vez más universales. Parece razonable pensar que la extensión de los valores afines a esta cultura tendrá un efecto directo sobre la movilización al igual que ocurre con las pautas de consumo y el modo de vida propio de los países desarrollados (Portes y Börözc, 1992).

Las divergencias entre países no son algo nuevo, al igual que tampoco la privación objetiva que afecta a la población en los países pobres del planeta es mayor que la que venían sufriendo anteriormente. Pero lo que sí es nuevo es la conciencia que se tiene sobre ello. La comparación con el estilo de vida occidental, con los modos y condiciones distintas de trabajo, referente que no existía antes, están detrás de esa percepción. De manera que no es la escasez en sí, sino el conocer que hay otros modos posibles lo que vuelve las condiciones insoportables. El contraste pondrá en marcha inevitablemente un sentimiento de irregularidad e injusticia que fragua en una frustración de las expectativas de orden ${ }^{17}$, 
que se acrece con el paso del tiempo. El descontento, sumado a otras circunstancias que den cabida a esa opción, llevará a buscar alternativas en el exterior. Un proceso y mecanismo que ya advirtió Tocqueville y cuya dinámica describe en los siguientes términos:

"Pacientemente aguantado mientras parecía de imposible reparación, un agravio llega a ser intolerable en cuanto la posibilidad de suprimirlo se presente en la mente de los hombres. Porque el simple hecho de que ciertos abusos se hayan remediado, atrae la atención sobre otros, que entonces parecen más indignantes; la gente puede que sufra menos, pero su sensibilidad se exacerba".

Abundando en esta línea, J. Cazorla (1989), en su estudio de la emigración española de los años cincuenta, defiende la importancia de los factores de índole psicológica, cultural o social que superará a los económicos. El aumento de las expectativas, fruto de un cambio de valores sumada a una mayor conciencia de la desigualdad existente, sensibilizan frente a la situación en el contexto y generan cada vez más descontento. El «efecto demostración», que opera a través de distintas vías, será fundamental en este proceso, si bien Cazorla recalca el papel que juega, en esa toma de conciencia, la percepción de una mejora ostensible que proyectan los emigrados.

En este sentido, también J. Arango (1992) y A. Izquierdo (1998) van a destacar, por encima de la desigualdad, el hecho de que las condiciones de vida en el lugar de origen se perciban como insoportables, en lo que sin duda es decisivo vislumbrar otras posibilidades pues éstas moverán, inevitablemente, a la "comparación" (Arango, 1992:1152). Si el ambiente es propicio al desplazamiento, es decir, coincide con una mentalidad que inclina en esa dirección - requisito previo y necesario según Jensen (1980)—, la opción de emigrar no suscitará demasiadas dudas ni supondrá — en circunstancias normales — una excesiva osadía.

Parece patente que las circunstancias y condiciones actuales reúnen sin excepción, y de modo ampliado, las características anotadas. Ahora bien, si hace tiempo, la distancia, como indican Cazorla y Montabes (1993), podía terciar aumentando o mermando el efecto del contraste, las estructuras de comunicación actuales, convertidos en su principal vehículo, soslayan la acción de esa variable restringiendo en mucho su valor.

Los media (anulando las distancias a escala de mirada y, con ello, quebrándolas en la mente), y la facilidad de transporte (que mina las distancias físicas)

\footnotetext{
${ }^{17}$ Entiendo por este concepto la contrariedad que deriva de contraponer la realidad efectiva $-l o$ que es- con la imagen que lo desplaza en cuanto norma y que opera ahora como referente de un mundo-existencia-ordenado (lo que debería ser).
} 
colocan al hombre ante el variado y prolijo escaparate del mundo. La profusión de reportajes, documentales y películas, sin solución de continuidad, induce la mezcla de contenidos creando una imagen mediatizada y deformada de la realidad (Augé, 1993). Cine y medios informativos, cuyos mensajes publicitarios son interpretados muchas veces en su literalidad, actúan en el exterior de las fronteras europeas como señuelo de un supuesto «mundo feliz», paradigma del bienes$\operatorname{tar}^{18}$. La rapidez y abaratamiento del coste de los traslados facilita enormemente la movilidad de mercancías y capitales, pero también la de las personas ${ }^{19}$, la de todo tipo de mensajes, y entre ellos los valores de referencia de los países avanzados. El proceso de globalización - financiera y económica- servirá de soporte a estos fenómenos y contribuye a acelerarlos. Todo ello deriva, finalmente, en una creciente «reducción» del mundo que irá pareja, y potencia a su vez, una homogeneización de los deseos.

«La idea de que el mundo definitivamente se ha agotado — reiteraba en un breve artículo V. Verdú ${ }^{21}$ - se cumple cuando al visitar la isla más remota aparece un nativo bebiendo Pepsi-cola.... Desde Nueva Orleans a Nueva Zelanda, desde Xi-an hasta Jaén, todo el mundo bebe los mismos refrescos, come Kentucky Fried Chiken, que también es de la Pepsi Co; aprecia las Reebock, las Nike o Adidas; mira la televisión a través de un Sony; aspira a un frigorífico de General Electric; tiene secadores Philips; hace fotocopias con Rank Xerox; no le extraña la palabra Microsoft; y desayuna con Kellogs».

Es ésta, sin duda, una experiencia que avala un número cada vez mayor de tratantes y turistas. El desarrollo del mercado mundial extiende un modelo uniformado de consumo que suspende las particularidades y cierra el mundo alrede-

\footnotetext{
${ }^{18} \mathrm{El}$ incremento constante de la publicidad potenciará sin duda este fenómeno. Datos del Informe del PNUD de 1998 indican que la cuenta del gasto anual en publicidad ha aumentado un $700 \%$ desde 1950 y supera hoy en un tercio el ritmo de crecimiento de la economía mundial. Muchos países en vías de desarrollo, como China, Indonesia e India, se han lanzado de modo compulsivo a la publicidad. Colombia, que ocupa el primer lugar en gasto en publicidad en relación con su ingreso nacional, junto a la república de Corea y Venezuela, suman en publicidad un porcentaje del PIB superior al de EEUU.

${ }^{19}$ Ya E. G. Ravenstein advirtió en sus famosas «Leyes de las Migraciones» (1885-89) el efecto positivo del avance de la tecnología y del transporte en el aumento de las migraciones, aspectos estrechamente vinculados al desarrollo económico, que actúa también en el mismo sentido: «¿Aumentan las migraciones? ¡Yo así lo creo! (...) Allí donde pude establecer una comparación, hallé que el aumento de los medios de locomoción y el desarrollo de las manufacturas y del comercio han conducido a un incremento de las migraciones». (Ravenstien, «The Laws, II, p.288, cit. por J. Arango, 1985:13)

20 V. Verdú, «El fin de la identidad», El PAÍ́S, 1 de mayo de 1997.
} 
dor de un reducido repertorio de etiquetas que se tornan símbolos y contraseñas. Pero, unidos a las grandes marcas, otros mensajes atraviesan las fronteras. El afán de consumo sí, pero también el individualismo, y más que eso, el culto a la libertad individual, la curiosidad y el afán por conocer, la rebeldía ante lo marcado, la transgresión como principio ${ }^{21}$, alcanzan todos los rincones del planeta a través de las ondas catódicas, el comercio y el turismo. El modelo de hombre (individual), de organización social y forma política (democracia), sistema económico (capitalismo) y estilo de vida (consumo) de los países avanzados, que tienen su cuna en el universo cultural europeo, han traspasado todas las fronteras convirtiéndose en un poderoso referente que induce un cambio de valores $\mathrm{y}$, por ende, de mentalidad. Todo ello va a provocar cambios en las expectativas y en las conductas.

No le faltaba razón a Sukarno al tachar de revolucionarios a los productores de cine norteamericanos, por su influjo en las apetencias y expectativas de la población de los países menos desarrollados ${ }^{22}$. Pero no únicamente porque las imágenes que difunden cine y televisión presenten un mundo en el que es usual el acceso a los bienes de consumo. El modelo que se propaga no incluye sólo disfrute de pertenencias y derroche de productos. Por debajo de esa «carcasa», hay un modelo de hombre y de sociedad, una mentalidad específica, otras pautas de conducta, un modo de ver y entender la existencia; un «fondo» particular, en suma, que se proyecta a través de un «formato» que también le es propio y que exige determinadas condiciones en el entorno. Y es que, un estilo de vida, implica un modo de entenderla, de concebirla, y una determinada postura frente a ella.

No sólo aumentan, por tanto, las expectativas «materiales». Crecen con ellas, y a mi juicio aún en mayor medida, las aspiraciones psicológicas y se añaden nuevas pretensiones que inclinan hacia otro «modo de vida». Un modo que tiene entre sus pivotes el individualismo y una mayor autonomía, el afán de singularizarse, la percepción de cierto grado de "libertad", y en el que la variable «cambio» - un vector de muy amplio rango que incluye entre sus facetas la inclinación a la «movilidad», al desplazamiento- tendrá valor por sí misma.

\footnotetext{
${ }^{21}$ Según Krzysztof Pomian, «la civilización europea es la única civilización que [...] ha hecho de la transgresión una manera de ser» (Pomian, K. (1994): «Europa y sus fronteras», Revista de Occidente, núm. p. 26).

${ }^{22} \mathrm{La}$ anécdota aparece recogida en el artículo de J. Cazorla y J. Montabes (1993:471). Poco podía prever entonces que las palabras de este dirigente acabarían cumpliéndose en parte unos cuantos años después. La crisis financiera que sufrió el sudeste asiático en el verano de 1997 provocó una grave crisis económica en Indonesia que dio lugar a numerosas protestas y conflictos. La devaluación de la moneda con el consiguiente incremento de la inflación y la escasez de alimentos motivó una escalada de violencia que llevó finalmente a la dimisión del presidente Suharto pocos meses después, en 1998.
} 
Cuando las distancias se reducen, el mundo también lo hace. Al tiempo que el propio espacio empieza a poblarse de extraños, lo lejano se halla más al alcance. Los media nos proyectan a todos los rincones y con ello todo lo que allí ocurre nos atañe. De esta manera se produce un doble bucle en la percepción que hace que nos sintamos «vinculados con lo extraño y desvinculados con lo próximo; indiferentes al entorno cercano y atentos al lejano» (Lamo de Espinosa, 1996: 136). Y así, no son sólo flujos de capital, marcas y mercancías, los que atraviesan las fronteras. Organismos internacionales, Congresos y ligas de voluntarios, expresan inquietudes, intereses y solidaridades - medio ambiente, minas antipersonales, atención primaria, instrucción, etc.- que no reconocen más límite que los del propio planeta. La locución «sin fronteras» se ha convertido en la consigna más reiterada y en enseña que identifica nuestro tiempo. Todo ello operará sobre los individuos en el sentido de potenciar la tendencia al cambio y al desplazamiento.

\section{A MODO DE CONCLUSIÓN}

En suma, los rasgos y pautas que reúnen las migraciones actuales, evidencian su distancia a una mera "ventaja económica", aunque sea ésta la que tiende a subrayarse como motivo principal, y es también, con frecuencia, la que más se verbaliza. A mi juicio, en los flujos actuales - exceptuando las movilizaciones que responden a la coacción física, una de cuyas manifestaciones son los flujos de refugiados-, tras la evidencia de los vínculos previos entre países, el peso fundamental recae sobre dos tipos de factores: culturales y sociales. Los primeros hacen referencia a la difusión de una serie de valores que provienen de la cultura occidental y a las pautas de consumo que también les son propias; los segundos se concretan en las redes transnacionales que ligan individuos en lugares distantes. Aquéllos contribuyen a ponerlas en marcha; éstos son los responsables de su continuidad y estabilidad.

La significación de los factores culturales está presente en las tesis de A. Portes y de S. Sassen que afirman la «penetración externa» de los países receptores en los de origen como requisito previo a los flujos migratorios, al derivar en vínculos "objetivos e ideológicos" entre ellos (Sassen,1988). En la fase actual, a mi juicio, y previa condición de ampliar la perspectiva sobre los movimientos migratorios - pues a la vista de la evolución de este proceso no podemos seguir reduciendo los desplazamiento de población únicamente a la vertiente económica一, estarían operando los tres mecanismos anotados por Portes y Börözc (1992) en cuanto modos de impulsar la movilización, si bien, el primero y el último incorporan algunas matizaciones.

El primero, la coacción física, directa o potencial, da lugar a los flujos de refugiados ${ }^{23}$. El segundo -incentivos económicos- además de observarse en 
los países en desarrollo que requieren de un mayor acopio de mano de obra extranjera (caso de los países del Sudeste asiático, previo a la crisis financiera de 1997, por ejemplo), se concreta en los estímulos y facilidades que reciben, para la emigración, los profesionales cualificados y personal técnico en los países avanzados.

Y, finalmente, la penetración cultural que, en mi opinión, englobaría un abanico más variado y amplio que el ya señalado por Portes y Börözc (1992) que enfatizan la difusión de patrones de consumo como eje fundamental. En ésta, mientras que dichos autores hacen hincapié en los aspectos, a fin de cuentas, también de índole económica (expectativas sobre pautas de consumo que no pueden ser satisfechas en economías de escasez), estimo que habría que considerar también la incidencia de una serie de valores que constituyen rasgos peculiares de la cultura moderna europea. Esto es, el cambio, la movilidad, la transgresión de lo estipulado, la ruptura, la lógica individualista, la incorporación del riesgo, etc., todos ellos fuertemente vinculados a la idea de logro, de progreso y de libertad. Así mismo y en esta línea, convendría no perder de vista otro factor, relacionado también con patrones culturales propios de los países desarrollados que, aunque aún se manifiesta de forma relativamente tangencial, puede ser otra fuente importante de desplazamientos; me refiero a la posición y situación de la mujer en muchos de los países emisores de flujos.

Por último, en lo que concierne a las redes sociales migratorias, parece evidente que su papel es clave y que tenderá a acentuarse aún más a medida que se continúen desarrollando. Es más, en mi opinión, la evolución de los movimientos migratorios apunta en la dirección que sostiene la corriente transnacionalista, enfoque en el que la migración se constituye en el mecanismo que posibilita expandir el ámbito de la existencia por encima de los limites territoriales que establecen las fronteras nacionales.

Desde mi punto de vista, dos limitaciones adicionales estarían afectando a los estudios en este campo. Una es la tendencia a privilegiar en la explicación los componentes económicos que, ineludiblemente, van a formar parte importante de los movimientos migratorios, entre otros motivos porque es un elemento necesario para el mantenimiento de la existencia. Pero esa razón que constituye, en sí misma, una condición formal — sin las que no pueden tener lugar determinados acontecimientos» (Simmel, 1977: 643) - no debería confundirnos, y

\footnotetext{
${ }^{23}$ En este caso, ese modo, si bien coincide con el mecanismo señalado por Portes y Börözc, $o b$. cit., en cuanto fuerza el desplazamiento de la población, difiere en que no siempre es promovido por un gobierno externo, así como en que la dirección que siguen no está tampoco determinada de antemano (si bien sí estará condicionada por los vínculos históricos establecidos en el pasado), elementos distintivos de ese modo en la fase histórica que Portes y Börözc señalan.
} 
(en)cubrir a los otros factores, empujándonos a aislarla como causa efectiva; un error frecuente y en el que es fácil caer cuando se trata de explicar las cosas a través de lo que las motiva, como ya advirtió Simmel. La otra, tiene que ver con ese presupuesto cardinal, que constituye sin duda el primer a priori, que privilegia la lógica sedentaria como la pauta de vida coherente y normalizada y que, en consecuencia, va a percibir la movilidad como lo anómalo, y a enfocarlo por ello en cuanto fenómeno singular y extraño.

Pero la realidad se resiste a ratificar aquellos presupuestos que tratan de confinarla a unos límites demasiado estrechos. Las circunstancias y condiciones de vida en numerosos lugares combinado con la lógica transnacional e itinerante del presente, dan nuevo impulso a los desplazamientos. Ni los obstáculos políticos, ni la distancia, podrán frenar esa tendencia a ampliar el horizonte vital. Menos aún cuando todas las demás fuerzas en este sistema global, que es el mundo de hoy, actúan en sentido contrario.

\section{REFERENCIAS BIBLIOGRÁFICAS}

ABAD MARQUEZ, L. (1993), "Nuevas formas de inmigración: un análisis de las relaciones interétnicas”, Política y Sociedad, n 12, pp. 45-59.

ACKERMAN, S. (1976), "Towards an Understanding of Emigrational Processes" en McNeill y Adams, Human Migration 1, pp. 287-303.

APARICIO, R. y A. TORNOS (coords.) (1997), Los peruanos que vienen, Madrid, Universidad Pontificia de Comillas.

ARANGO, J. (1985), «Las 'Leyes de las Migraciones' de E. G. Ravenstein, cien años después», Revista Española de Investigaciones Sociológicas, ${ }^{\circ} 32$, pp. 7-26.

(1992), «Las migraciones internacionales a fines del siglo XX: realidad y teoría», en VV.AA., Escritos de Teoría Sociológica en homenaje a L. R.. Zúñiga, Madrid, Centro de Investigaciones Sociológicas, pp. 1145-1164.

(1993), «EL «Sur» en el sistema migratorio europeo. Evolución reciente y perspectivas», Política y Sociedad, $n^{\circ} 12$, pp. 7-19.

AUGÉ, M. (1993), «Espacio y alteridad», Revista de Occidente, núm. 140, pp. 13-34.

BASCH, L., N. GLICK SCHILLER y C. SZANTON BLANC (1994), Nations Unbound. Transnational Projects, Postcolonial Predicaments and Deterritorialized Nation-States, Gordon and Breach Science Publishers.

BAUMAN, Z. (1994), "Racismo, antirracismo y progreso moral", Debats, n 47, pp. 51-58.

BÖHNING, W.R. (1984), Studies in International Labor Migration, London, MacMillan. 
BOYD, M. (1989), «Family and Personal Networks in International Migration: Recent Developments and New Agendas», en International Migration Review, vol. 23, $\mathrm{n}^{\circ} 3$, New York, Center for Migrations Studies, pp. 638-670.

CASTILLO C. J. (1992), «Teorías sociológicas de las migraciones humanas: diversidad e integración», en VVAA, Escritos de teoría Sociológica en homenaje a Luis Rodríguez. Zúñiga, Madrid, Centro de Investigaciones Sociológicas, pp. 261-278.

CASTLES, S., H. BOOTH y T. WALLACE (1984), Here for Good. Westerns Europe's New Ethnic Minorities, Londres, Pluto Press.

CASTles, S. y M. MILlER (1993), The Age of Migration. Population Movements in Modern World, Londres, MacMillan.

CAZORLA PÉREZ, J. (1989), Retorno al Sur, Madrid, Siglo XXI.

CAZORLA, J. y J. MONTABES (1993), «Cambio social y emigración en el Mediterráneo occidental», en VV.AA Explosión demográfica, empleo y trabajadores emigrantes en el Mediterráneo occidental, Granada, Universidad de Granada y AECI, pp. 471-482.

COLEMAN, J. (1988), «Social capital in the creation of human capital», American Journal of Sociology, $\mathrm{n}^{\circ} 94$.

CRIADO, Mª.J. (1999), La línea quebrada. Historias de vida de migrantes, Tesis doctoral, U.C.M.

IZQUIERDO ESCRIBANO, A. (1992), La Inmigración en España, 1980-1990, Madrid, Ministerio de Trabajo y Seguridad Social.

(1996), «Desafíos y sorpresas en las migraciones internacionales, en III Encuentro Internacional sobre Servicios Sociales. La Tolerancia y la Intervención Social, Valencia, Ed. Bancaixa.

(1998), «Las migraciones en Europa y en España», en VV.AA. España, sociedad industrial avanzada, vista por los nuevos sociólogos» Madrid, Real Academia de CC. Morales y Políticas, pp. 207-244.

FAWCETT, J.T. (1989), «Networks, Linkages and Migration Systems», International Migration Review, vol. 23, $\mathrm{n}^{\circ}$. 2, New York, Center for Migration Studies, pp. 671-680.

GLICK-SCHILLER, N., L. BASCH y C. BLANC-SZANTON (1992), «Transnationalism: A New Analytic Framework for Understanding Migration», en mismas autoras (ed.): Towards a Transnational Perspective on Migration: Race, Class, Ethnicity and Nationalism Reconsidered, New York, The New York Academy of Sciences.

JENSEN, C. J. (1970), Reading in the Sociology of Migration, Oxford, Pergamon Press.

LAMO DE ESPINOSA, E. (1995), «Fronteras culturales» en mismo autor (ed.) Culturas, estados, ciudadanos. Una aproximación al multiculturalismo en Europa, Madrid, Alianza, pp. 13-80.

(1996), Sociedades de cultura, sociedades de ciencia, Oviedo, Ediciones Nobel. 
LÓPEZ, B. (1992), «Las migraciones magrebíes y España», Alfoz, núm. 1991-92, pp. 52-59.

MARTÍN SERRANO, M. (1993), «Los efectos sociales de la política inmigratoria», Política y Sociedad, $\mathrm{n}^{\circ} 12$, pp. 37-43.

MARTÍNEZ VEIGA, U. (1997), La integración social de los inmigrantes extranjeros en España, Madrid, Trotta.

MASSEY, D. (1987), «Understanding Mexican Migration to the United States», American Journal of Sociology, $\mathrm{n}^{\circ}$ 92, pp. 1372-1403.

MASSEY, D. y F. GARCÍA ESPAÑA (1987), «Social structure of migration», Science, $n^{\circ} 237$ : 733-738.

MASSEY, D., R. ALARCÓN, J. DURAND y H. GONZÁLEZ (1987), Return to Aztlan: The Social Process of International Migration from Western Mexico, Berkeley, University of California Press.

MASSEY, D., J. ARANGO, et al. (1993), «Theories of International Migration: A Review and Appraisal», Population and Development Review, n 19, pp. 431-466.

POMIAN, K. (1994), «Europa y sus fronteras», Revista de Occidente, n 157, pp. 25-50.

PORTES, A. (1979), «Illegal Immigration and the International System», Social Problems, $\mathrm{n}^{\circ} 26$. (1995), The Economy Socilogy of Immigration, New York, Russell Sage.

PORTES, A. y R.L. BACH (1985), Latin Journey: Cuban and Mexican Immigrants in United States, Berkeley, Universiy of California Press.

PORTES, A. y J. BÖRÖCZ (1992), «Inmigración contemporánea: perspectivas teóricas sobre sus determinantes y modos de acceso», Alfoz., n $91 / 92$, pp. 20-35.

PORTES, A. y R. RUMBAUT (1990), Immigrant America, Berkeley, University of California Press.

PIORE, M. (1979), Birds of passage. Migrant labor and industrial societies, New York, Cambridge University Press.

SASSEN, S. (1988), The Mobility of Labor and Capital: a Study in International Investment and Labor Flow, Cambridge University Press (La movilidad del trabajo y del Capital, Madrid, Ministerio de Trabajo y S.S., 1993).

(1994), «America's Immigration Problem» en F. C. Pinans, y H. J. Ehrlich, (eds) Race and Ethnic Conflict, Bulder, Westview Press.

SOLÉ, C. (1995), Discriminación racial en el mercado de trabajo, Madrid, Consejo Económico y Social.

SOPEMI (1998), Trends in International Migration, París, OECD. 
TAYLOR, Ch. (1992), Multiculturalism and the «Politics of Recognition», New Jersey, Princeton University Press (traducción en Fondo de Cultura Económica, 1993).

TOURAINE, A. (1995), «¿Qué es una sociedad multicultural», Claves, núm. 57, pp. 14-25.

VERDÚ, V. (1997), «El fin de la identidad», en EL PAÍS, I de mayo.

WEBER, M. (1990), «La situación de los trabajadores agrícolas en la Alemania del Este del Elba. Visión general (1892), Revista Española de Investigaciones Sociólogicas, núm. 49, pp. 233-255.

(1987), «International Emigration and the Third World» en W. Alonso (ed) Population in an Interacting World, Harvard University.

WOOD, Ch. H. (1992), «Modelos opuestos en el estudio de la Inmigración», Alfoz, nº 91/92, pp. 35-39.

SUMMARY. This article analyses the most differences between present flows and former migrant movements. The main factors for their outset are then revised; stress is placed on the spreading influence of social and cultural factors. The process of globalisation support and boots these process.

E-mail: mjcriado@jazzfree.com 